\title{
A concepção de alfabetização em programas federais: tensões e (in)certezas da Política Nacional De Alfabetização (2016-2019)
}

\author{
Silvia Cristiane Alfonso Viedes ${ }^{1}$ \\ https://orcid.org/0000-0002-5048-0562 \\ Sandra Novais Sousa ${ }^{2}$ \\ http://orcid.org/0000-0002-5965-1954 \\ Maria Alice De Miranda Aranda ${ }^{3}$ \\ http://orcid.org/0000-0003-2561-7579
}

\section{Resumo}

O artigo objetiva analisar as concepções de alfabetização implícitas no Pacto Nacional pela Alfabetização na Idade Certa (Pnaic) e Programa Mais Alfabetização (PMAlfa), que compõem a Política Nacional de Alfabetização, reconfigurada em 2019 no governo Bolsonaro (2019). Para tanto, utilizou-se como procedimentos metodológicos a análise de documentos, tendo como fontes a legislação educacional, os cadernos de programas de formação de alfabetizadores e os documentos que embasam as políticas de avaliação ligadas a esses programas. Como resultados, aponta-se que as mudanças nas políticas de alfabetização ocorridas a partir de 2016 são provenientes de inflexões nas concepções de alfabetização e não exclusivamente dos resultados das avaliações em larga escala. De aprendizagem conceitual de um sistema notacional, no Pnaic, a alfabetização passou a ser considerada a aprendizagem de um código, deslocando-se a ênfase da aprendizagem para o ensino e antecipando para o $1^{\circ}$ ano do ensino fundamental o momento de consolidação da alfabetização.

Palavras-chave: Alfabetização. Avaliação. Políticas Públicas em Educação. Programa Governamental.

\begin{abstract}
The article aims to analyze the conceptions of literacy implicit in the National Pact for Literacy at the Right Age (PNAIC) and More Literacy Program (PMAlfa), that make up the National Literacy Policy, reconfigured in 2019 under the Bolsonaro government (2019). Therefore, the methodological procedures used were document analysis, having as sources the educational legislation, the program notebooks of literacy formation and the documents that underpin the policies of evaluation linked to these programs. As results, it points that the changes in literacy policies that occurred from 2016 come from inflections in literacy conceptions and not exclusively from the results of large-scale evaluations. From conceptual learning of a notational system, in Pnaic, literacy became considered the learning of a code, shifting the emphasis from learning to teaching and anticipating for the 1st grade of elementary school the moment of consolidation of literacy.
\end{abstract}

Keywords: Literacy. Evaluation. Public Policies in Education. Government Program.

\footnotetext{
${ }^{1}$ Doutoranda em Educação pelo PPGEDU/ Universidade Federal da Grande Dourados (UFGD), Linha de Pesquisa Políticas e Gestão da Educação. Mestre em Educação pela Universidade Estadual de Mato Grosso do Sul (UEMS), licenciada em Pedagogia pela Universidade Federal de Mato Grosso do Sul (UFMS). E-mail: silviedes@hotmail.com

${ }^{2}$ Doutora em Educação pela Universidade Federal de Mato Grosso do Sul (UFMS), mestre em Educação pela Universidade Estadual de Mato Grosso do Sul (UEMS). É professora da Faculdade de Educação da Universidade Federal de Mato Grosso do Sul (UFMS). E-mail: sandra.novais@ufms.br

${ }^{3}$ Docente do Programa de Pós-Graduação em Educação da Universidade Federal da Grande Dourados - Mestrado e Doutorado (PPGEDU/ UFGD). Pós- Doutora em Educação pelo Programa Nacional de Pós-Doutorado/Coordenação de Aperfeiçoamento de Pessoal de Nível Superior (PNPD/CAPES) na Universidade Federal de Uberlândia (UFU). E-mail: mariaaranda@ufgd.edu.br
} 


\section{Introdução}

Nesse estudo, objetivamos analisar as concepções de alfabetização implícitas na Política Nacional de Alfabetização, por meio da análise dos programas Pacto Nacional pela Alfabetização na Idade Certa (Pnaic) e Programa Mais Alfabetização (PMAlfa), e, ainda, da reconfiguração dada à referida política com a publicação do Decreto $n^{\circ} 9.765$, de 11 de abril de 2019 .

O Pnaic foi lançado por meio da Portaria $n^{\circ}$ 867, de 4 de julho de 2012 (BRASIL, 2012a), no início do primeiro mandato de Dilma Vana Rousseff (PT), que ficou à frente do Governo Federal de 2011 a 31 de agosto de 2016, quando sofreu processo de impeachment e seu vice-presidente, Michel Miguel Elias Temer Lulia (PMDB), assumiu a presidência. Trata-se de um programa voltado para os três primeiros anos do ensino fundamental, denominados no programa de "ciclo de alfabetização ${ }^{4 "}$ ", e consiste, basicamente, em "[...] um acordo formal assumido pelo Governo Federal, estados, municípios e entidades para firmar o compromisso de alfabetizar crianças até, no máximo, 8 anos de idade, ao final do ciclo de alfabetização.” (BRASIL, 2012b, p. 5). Para tanto, o programa foi estruturado em quatro eixos de atuação: 1) formação dos professores alfabetizadores, realizada de forma presencial e mediada por orientadores de estudo, que, por sua vez, também recebem formação específica; 2) envio de materiais didáticos, obras literárias, obras de apoio pedagógico, jogos e tecnologias educacionais às escolas; 3) criação de uma política de avaliação em larga escala, a Avaliação Nacional da Alfabetização (ANA); 4) gestão, controle social e mobilização. (BRASIL, 2012b; VIÉDES, 2015).

Seis anos depois do lançamento do Pnaic, o PMAlfa foi instituído, a menos de um ano do final do mandato de Michel Temer e como parte do que foi então chamado de Política Nacional de Alfabetização. É importante destacar que o Pnaic não foi oficialmente revogado, mas passou a sofrer severas críticas logo no início dessa gestão, em 2017, entre elas a do diretor de currículo e educação integral do MEC, à época, Raph Gomes Alves, que considerava que o Pnaic “[...] teve foco em concepções teóricas muito dissociadas da prática, trazia materiais padronizados para todo o País, além de ter uma gestão muito centrada nas universidades e pouco monitoramento." (ALVES, 2017, não paginado).

No entanto, para Sousa e Nogueira (2016) um dos diferenciais do Pnaic em relação a outros programas nacionais de formação de professores alfabetizadores foi justamente a parceria com um maior número de universidades e centros de pesquisa na área de alfabetização e linguagem, como o Centro de Estudos em Educação e Linguagem (CEEL), da Universidade Federal de Pernambuco, e o Centro de Alfabetização, Leitura e Escrita (Ceale), da Universidade Federal de Minas Gerais.

Em 2018, o MEC anunciou modificações importantes nas políticas de avaliação em larga escala que atingem os anos iniciais do ensino fundamental, antecipando o que seria a "idade certa" para a consolidação da alfabetização para os 7 anos, ao final do $2^{\circ}$ ano do ensino fundamental, ao invés de 8 anos de idade e ao final do $3^{\circ}$ ano, como previsto no Pnaic.

Assim, o Instituto Nacional de Estudos e Pesquisas Educacionais Anísio Teixeira (Inep) revisou, a pedido do governo, as matrizes de referência das avaliações, a fim de adequá-las à Base Nacional Comum Curricular

\footnotetext{
4 "Utiliza-se na Educação brasileira a palavra ciclo para designar cada um dos níveis em que se divide o tempo do ensino público. [...] consequentemente, o tempo escolar passa a ser organizado em fluxos mais flexíveis, mais longos e mais adequados às metas propostas pelo currículo escolar. Nesse sentido, o ciclo de alfabetização nos anos iniciais do Ensino Fundamental é compreendido como um tempo sequencial de três anos, ou seja, sem interrupções, por se considerar, pela complexidade da alfabetização, que raramente as crianças conseguem construir todos os saberes fundamentais para o domínio da leitura e da escrita alfabética em apenas um ano letivo.”(SILVA, 2014, p. 1).
} 
(BNCC), sendo que "[...] as siglas ANA, Prova Brasil, entre outras, deixam de existir e todas as avaliações passam a ser identificadas pelo nome Saeb, acompanhado das etapas, áreas de conhecimento e tipos de instrumentos envolvidos.” (MINISTÉRIO DA EDUCAÇÃO, 2018, não paginado). Enquanto a ANA foi idealizada de modo a ser censitária e anual, as avaliações do Sistema de Avaliação da Educação Básica (Saeb) são bianuais, concentrando as aplicações nos anos ímpares e a divulgação dos resultados nos anos pares. Outro detalhe importante é que a etapa da Educação Infantil, nessa reestruturação do Saeb, também passará a ser avaliada, não com testes para as crianças, mas com questionários aplicados a professores e gestores.

Em 2019, quando Jair Messias Bolsonaro assumiu a presidência da República, houve uma reconfiguração da chamada "Política Nacional de Alfabetização", relançada por meio da publicação do Decreto n 9.765, de 11 de abril de 2019, assinado pelo ministro da Educação Abraham Bragança de Vasconcellos Weintraub, segundo ${ }^{5}$ a assumir a pasta do MEC após 100 dias de governo. Nessa política, que se baseia em outra concepção de alfabetização, passase a considerar que ao final do $1^{\circ}$ ano do ensino fundamental as crianças devem estar plenamente alfabetizadas. De forma semelhante à política anterior, os entes federados foram convidados a aderir à política lançada pelo Governo Federal, sem que, oficialmente, o Pacto anterior tivesse sido revogado.

Essas inflexões aqui brevemente mencionadas demonstram que há diferentes concepções de alfabetização em pauta, o que leva a diferentes entendimentos de como, e em que momento da escolarização, deveriam ser avaliados os resultados do ensino da leitura e da escrita nas redes públicas de educação.

Diante disso, propomo-nos a analisar as tensões e incertezas decorrentes das mudanças observadas nas políticas educacionais nesse curto espaço de tempo, advindas de posicionamentos diferentes em relação à alfabetização. Organizamos os resultados dessa análise em duas seções: na primeira, discutimos em uma perspectiva histórica e sociológica o conceito de alfabetização; na segunda, trazemos ao debate o que foi possível inferir, a partir da leitura dos documentos oficiais, sobre qual a concepção privilegiada nas políticas em pauta.

\section{Concepções de alfabetização: uma abordagem teórica}

As concepções de alfabetização estão intrinsecamente relacionadas a como se compreende a língua escrita: como sistema notacional ${ }^{6}$, a exemplo do Pnaic, ou como código, como foi considerado no PMAlfa e no Decreto $n^{0}$ 9.765, como detalharemos na próxima seção. As consequências de se partir de uma dessas definições não são apenas terminológicas, uma vez que influenciam, na esfera das políticas educacionais, os programas de formação de alfabetizadores, as políticas de avaliação, aquisição e distribuição de material didático e paradidático, as matrizes de referência e a análise dos resultados das avaliações em larga escala, o tempo considerado apropriado para a consolidação do processo de alfabetização e as metodologias estimadas como mais eficazes para o ensino.

\footnotetext{
${ }^{5}$ De $1^{\text {o }}$ de janeiro de 2019, posse do novo governo, até 8 de abril de 2019, a pasta do Ministério da Educação ficou sob a gestão de Ricardo Velez Rodriguez.

6 A notação refere-se às "marcas externas ou símbolos registrados sobre superfícies, que atuam em substituição a objetos ou eventos do mundo real" e constitui-se em uma capacidade exclusiva do ser humano, que ensina "às gerações seguintes os princípios de uso e habilidades para tratarmos a realidade através de sistemas simbólicos tão complexos como a notação alfabética, a notação numérica, a cartográfica e a musical." (MORAIS, 2005, p. 32). Um sistema notacional, dessa forma, consiste em um sistema simbólico convencionalizado, que atende a certas propriedades, para poder substituir objetos ou eventos da realidade. As marcas desse sistema simbólico não são uma cópia ou réplica do real, mas uma representação arbitrária, em que alguns elementos são priorizados e outros não. Como exemplo, Morais (2005) cita a cartografia moderna, que, para registrar a presença de capitais, cidades ou fronteiras, "usa símbolos completamente arbitrários (bolinhas de tamanhos e cores diferentes, quadradinhos, linhas pontilhadas, etc.), cujos significados são convencionalizados numa legenda, mas que nada guardam da aparência das cidades ou vilas que substituem".
} 
Ao conceber a língua escrita como código e a leitura como decodificação, são o método e a técnica que ganham maior destaque. Consequentemente, os programas de formação passam a privilegiar o treinamento para utilização eficaz de um método, e as avaliações tendem a usar como critérios de qualidade a maior ou menor proximidade dos resultados com o que era esperado com a aplicação de tal método.

Na história da educação, tivemos momentos em que ora os métodos sintéticos (alfabético, silábico, fônico), ora os métodos analíticos (palavração, sentenciação, contos e historietas), foram considerados mais eficazes. (FRADE 2005). Todos eles, no entanto, possuem em comum o fato de se centrarem no ensino, ou seja, é a atuação do professor que ganha destaque no processo de apreensão do código escrito e de sua decodificação, sendo o professor, geralmente com o apoio de materiais didáticos - com ênfase nas cartilhas e em textos construídos intencionalmente para facilitar a operacionalização do método - aquele que decidirá a ordem e o momento apropriado de apresentar os elementos da língua a serem aprendidos.

Nessa concepção, portanto, para ensinar de forma eficaz é suficiente que o professor siga o passo-a-passo do método ou técnica, e a qualidade desse ensino é verificada tendo como parâmetro o quão fielmente o sujeito aprendente consegue reproduzir aquilo que foi ensinado, pois se trata de “[ ...] um ensino baseado na memorização, na reprodução de modelos e na cópia, que tem como princípio a aprendizagem de um código [...]" (SOUSA; NOGUEIRA, 2016, p. 81).

Em outra perspectiva, ao compreender a escrita como sistema notacional, concebe-se que a alfabetização é um processo complexo que requer que o aprendiz compreenda as propriedades do Sistema de Escrita Alfabética (SEA) para poder usar suas convenções, lendo e escrevendo quaisquer palavras. Desloca-se, assim, a ênfase do ensino para a aprendizagem, isto é, para as formas com que o sujeito se apropria e (re)constrói conceitualmente seu significado, partindo-se do princípio que a aprendizagem do SEA “[...] se converte na apropriação de um novo objeto de conhecimento, ou seja, em uma aprendizagem conceitual.” (FERREIRO, 2011, p. 19).

Espera-se, sob essa ótica, que um ensino de qualidade do SEA esteja pautado no trabalho de um professor alfabetizador que compreenda esses processos de aprendizagem e reconstrução conceitual, tendo domínio das teorias que explicam como os sujeitos aprendem, a fim de promover, criar e recriar práticas que facilitem e medeiem essa apropriação, levando-se em consideração as singularidades dos sujeitos aprendentes, o que, por extensão, não seria coerente com a aplicação de um único método a todos os alunos, sem diferenciação, mas de quantos métodos forem necessários diante das especificidades de cada criança.

A avaliação da qualidade ou eficácia do ensino aprendizagem nessa concepção também é compreendida de um ponto de vista processual, tornando mais complexa a aplicação de uma avaliação em larga escala, pois esse modelo dificilmente daria conta de abranger as diversas facetas de diagnóstico do nível de apropriação do alfabetizando em relação ao SEA.

De fato, o Documento Básico da Avaliação Nacional da Alfabetização (ANA) apontava “[...] os limites metodológicos e técnicos relacionados à construção de itens objetivos, de múltipla escolha, para a leitura, ou de itens de escrita que necessitam de uma matriz de correção que focaliza o texto como produto, e não como processo [...]" (BRASIL, 2013, p. 15).

Esse reconhecimento está em consonância com a compreensão de que o fato de uma criança não ter conseguido ler ou escrever convencionalmente durante a realização de uma avaliação não significa, automaticamente, que não tenha tido avanços em sua apropriação do sistema de escrita, haja vista que somente a consideração de seu percurso 
de aprendizagem, ou seja, de seu ponto de partida e do que já construiu até aquele momento, de acordo com suas especificidades, é que poderia determinar se ela recebeu ou não um ensino de qualidade.

No entanto, por não se constituir em uma política de Estado, mas de governo, assim que houve a troca de gestores, tanto na presidência da República, com a posse de Michel Temer, quanto nos órgãos responsáveis pela articulação dos eixos de sustentação do Pnaic já mencionados, entre eles a avaliação, os resultados da ANA foram utilizados como um parâmetro para a substituição da proposta para a alfabetização construída até então.

Na Base Nacional Comum Curricular (BNCC) 7 apresentada em 2017 pelo Governo Federal, outras concepções de ensino da língua escrita foram mobilizadas. Porém, a BNCC não consistiu em um documento consensual nem entre a comunidade científica que investiga o campo da Educação e, mais particularmente, da alfabetização, nem entre as entidades representativas de pesquisadores e professores, como a Associação Brasileira de Alfabetização (Abalf), Associação Nacional de Pós-Graduação e Pesquisa em Educação (ANPEd), Associação Nacional pela Formação dos Profissionais da Educação (Anfope) e Associação Nacional de Política e Administração da Educação (Anpae), entre outras.

Dentre as críticas à versão da BNCC homologada pelo governo, em uma carta aberta do "Projeto Leitura e Escrita na Educação Infantil", que consistiu em uma parceria firmada entre três universidades - Universidade Federal de Minas Gerais (UFMG), Universidade Federal do Rio de Janeiro (UFRJ) e Universidade Federal do Estado do Rio de Janeiro (UNIRIO) - e o MEC, por meio da Secretaria de Educação Básica (SEB) e da Coordenação Geral de Educação Infantil (Coedi), os responsáveis pelo referido projeto, que haviam participado da elaboração da segunda versão da BNCC, apontam:

\begin{abstract}
A afirmação de que "A literatura introduz a criança na escrita" pode resultar em uma indesejada interpretação de que o texto literário deva ser empregado, nas práticas pedagógicas, com a finalidade de ensinar as relações entre grafemas e fonemas, as regularidades e irregularidades do sistema de escrita, etc. [...] A afirmação de que a escrita representa a oralidade está incorreta, do ponto de vista teórico. A escrita representa a língua e é justamente por isso que comporta as diferenças regionais e dos diversos grupos sociais. Esse erro conceitual pode induzir a práticas pedagógicas inadequadas como, por exemplo, forjar uma relação binária entre sons e letras (PROJETO LEITURA E ESCRITA NA EDUCAÇÃO INFANTIL, 2017, p. 3).
\end{abstract}

Percebe-se, assim, que as críticas dos responsáveis pelo Projeto Leitura e Escrita na Educação Infantil tocam em pontos nevrálgicos das diferenças entre as concepções de alfabetização tratadas nesta seção. A escolha dos termos utilizados na BNCC, como "introdução da criança na cultura escrita", revela que se concebe como escrita a reprodução do código, desconsiderando-se as apropriações subjetivas que as crianças vão fazendo sobre esse objeto cultural mesmo antes de adentrarem às instituições de ensino.

Na segunda versão da BNCC, em que os princípios que constituíam o Pnaic embasavam a proposta para a Educação Infantil e o ciclo de alfabetização, a aprendizagem da língua escrita havia sido tratada como uma aprendizagem conceitual, que não se resume ao ensino direto das relações entre grafemas e fonemas, embora esse ensino faça parte do processo, sendo priorizadas as estratégias de aproximação da criança com os usos sociais de textos escritos.

\footnotetext{
A Base Nacional Comum Curricular (BNCC) "é documento governamental normativo que define o conjunto de conteúdos considerados est senciais a todos os alunos em todas as etapas e modalidades da Educação Básica.” (HEINSFELD, SILVA, 2018, p. 669). A primeira e a segunda versões do documento foram elaboradas a partir de consulta pública e terceira, que foi homologada em 2017, consiste na versão instituída pelo governo, que sofreu importantes alterações em relação às primeiras versões.
} 
Diante dessa breve contextualização, conforme o objetivo desse estudo elencado anteriormente, buscamos na próxima seção analisar as inflexões da concepção de alfabetização implícita nos documentos oficiais que norteiam a Política Nacional de Alfabetização (2017-2019).

\section{A concepção de alfabetização encontrada no Pnaic, PMAlfa e Decreto $n^{0}$ 9.765/2011}

Para compreender o que denominamos como inflexões da concepção de alfabetização na Política Nacional de Alfabetização (2017-2019), faz-se necessário fazer uma breve incursão histórica. O Pacto Nacional pela Alfabetização na Idade Certa (Pnaic) surge em 2012, como uma das ações promovidas pelo MEC para consolidar as diretrizes do Plano de Metas Compromisso todos pela Educação, lançado no Governo Luis Inácio Lula da Silva (PT) em 2007 (BRASIL, 2007a), de alfabetizar as crianças até os oito anos de idade.

No caderno de formação intitulado "Aprendizagem do sistema de escrita alfabética" a alfabetização é compreendida como "um processo cognitivo complexo" de aprendizagem de "[...] um sistema notacional, no qual as habilidades perceptivas e motoras não têm um peso fundamental, conceito bem diferente de 'código"”. (BRASIL, 2012c, p. 7). As implicações dessa concepção se evidenciam no Pnaic pela forma com que são concebidas as práticas de alfabetização. Por considerar a escrita alfabética um sistema notacional e seu aprendizado um processo, entende-se que o professor alfabetizador precisa "[...] recriar as metodologias de alfabetização, garantindo um ensino sistemático que, através de atividades reflexivas, desafiem o aprendiz a compreender como a escrita alfabética funciona, para poder dominar suas convenções letra-som.” (BRASIL, 2012c, p. 8).

Assim, compreende-se a opção, nesse programa, pela nomenclatura "ciclo de alfabetização", uma vez que se considera que a complexidade desse processo demanda conceber a criança como um sujeito ativo da aprendizagem, não um receptor de conteúdos transmitidos pelo professor, que precisa reconstruir intelectualmente o funcionamento do sistema de escrita alfabética e não somente memorizar e reproduzir as combinações possíveis entre as letras e sílabas.

Nessa perspectiva, só faria sentido o ensino das convenções ortográficas a partir do momento em que o alfabetizando tivesse compreendido esse funcionamento, o que poderia ocorrer ao final do primeiro ano ou somente nos dois últimos anos desse ciclo, a depender do ritmo de aprendizagem de cada criança. Isso justificaria também a opção da aplicação da ANA somente ao final do $3^{\circ}$ ano do ensino fundamental, bem como a ênfase em não direcionar o ensino para um método único, pois esse processo envolve fatores sociais, históricos, econômicos e subjetivos complexos, incluindo a consideração de quais oportunidades de aproximação com a cultura escrita essa criança teve, tanto antes de ingressar na escola como depois de inserida em uma instituição de ensino.

No Documento Básico da ANA, a referência a essa complexidade aparece de forma explícita:

A Avaliação Nacional da Alfabetização (ANA) produzirá indicadores que contribuam para o processo de alfabetização nas escolas públicas brasileiras. Para tanto, assume-se uma avaliação para além da aplicação do teste de desempenho ao estudante, propondo-se, também, uma análise das condições de escolaridade que esse aluno teve, ou não, para desenvolver esses saberes (BRASIL, 2013, p. 7).

Nos cadernos do Pnaic, portanto, há críticas relacionadas à visão da alfabetização como aprendizagem de um código, à ênfase nos métodos de ensino e ao uso de cartilhas e textos descontextualizados de seu uso social: 
Segundo aqueles métodos - por exemplo, o método silábico ou o fônico -, a criança seria uma "tábula rasa" que, repetindo informações prontas, transmitidas pela professora ou pelo autor da cartilha, se alfabetizaria sem ter que modificar suas ideias prévias sobre a escrita, de modo a compreender como o alfabeto funciona. De acordo com essa visão, para aprender a ler e a escrever, seria preciso apenas ter habilidades perceptivas e motoras (discriminação visual, discriminação auditiva, coordenação motora fina etc.) e receber, em doses homeopáticas, informações sobre as letras e sobre o seu valor sonoro. [...] Muitas crianças, por decorarem a cartilha, sabiam os nomes de todas as letras, memorizavam todas as sílabas, mas continuavam sem compreender "como as letras funcionam". Além disso, todas as crianças eram expostas a falsos textos (por exemplo, "EU LEIO. ELA LÊ. LALÁ LEU. LULA LIA") e privadas da oportunidade de avançar em seus conhecimentos sobre os textos escritos reais, isto é, de avançar em seu nível de letramento, enquanto aprendiam a escrita alfabética (BRASIL, 2012c, p. 7).

Assim, lançado a partir desses princípios e de acordo com essas concepções teóricas, é de esperar que a primeira aplicação da ANA, ocorrida em 2013, apenas um ano após o lançamento do Pnaic, tivesse um cunho mais diagnóstico do que classificatório, uma vez que seus resultados não refletiriam de forma direta os efeitos do programa de formação, mas as condições de ensino anteriores. Nessa lógica, somente a partir da quarta edição da avaliação de larga escala, em 2016, se fosse seguido o modelo censitário e anual idealizado no lançamento do programa, poder-se-ia, minimamente, esperar que alguns resultados positivos tivessem sido alcançados pelas crianças que iniciaram seu ciclo de alfabetização em 2013.

De fato, no Relatório da Avaliação Nacional da Alfabetização (ANA) 2013-2014, produzido pelo Inep, indica-se que os resultados aferidos pelas duas primeiras edições da avaliação poderiam se converter em um “[...] valioso instrumento de consultas e subsídios para análises e planejamentos”, e não, simplesmente, como um indicativo de eficácia ou ineficácia do Pnaic. (BRASIL, 2015, p. 14).

A edição de 2013, denominada aplicação-piloto, foi realizada em um único dia e analisada a partir de determinada matriz de referência. Na versão de 2014, houve modificações na metodologia de correção dos itens de escrita e a escala de referência foi alterada. Dessa forma,

[...] os resultados dos dois anos não são comparáveis. Assim, um mesmo desempenho em Escrita para os dois ciclos não necessariamente representa o domínio das mesmas habilidades; não é possível, também, falar em aumento ou redução de médias ou de quantidade de habilidades dominadas de um ano para o outro. Como dito, os resultados de Escrita de 2014 não são comparáveis com os resultados de 2013 (BRASIL, 2015, p. 16).

Dessa forma, tanto os resultados de 2013 não refletem os efeitos do Pnaic na formação dos professores alfabetizadores, quanto os resultados de 2014 não podem, na mesma perspectiva, serem utilizados para comparar avanços ou retrocessos na alfabetização atribuíveis ao programa.

Em 2015 não houve aplicação da ANA. Somente em 2018, já durante o governo Temer, foi publicado relatório sobre os resultados da edição aplicada em 2016, que, embora tenha sido planejada e organizada no governo Dilma, ocorreu nos primeiros meses do governo Temer, que não realizou, após isso, nenhuma outra edição da avaliação, ainda que a previsão do Pnaic fosse de tornar a ANA censitária e anual.

O documento também informa que "[...] devido às especificidades da metodologia de cálculo empregada, criou-se uma escala de proficiência própria para cada edição, configurando escalas não comparáveis." (BRASIL, 2018c, p. 15), ou seja, os resultados da edição 2016, no que se refere à leitura e escrita, não poderiam ser comparados, utilizando-se a mesma escala de proficiência, com os resultados das edições anteriores. 
A leitura dos relatórios nos permite analisar que em 2018 já podem ser percebidas sutis inflexões na concepção de alfabetização que embasava o Pnaic. Lê-se, no Documento Básico da ANA, produzido durante a gestão Dilma Rousseff e com a participação das universidades e centros de pesquisa em linguagem e alfabetização:

É importante considerar, no entanto, que a apropriação da escrita alfabética não significa que o sujeito esteja alfabetizado. Essa é uma aprendizagem fundamental, mas, para que os indivíduos possam ler e produzir textos com autonomia, é necessário que eles consolidem as correspondências grafofônicas, ao mesmo tempo que vivenciem atividades de leitura e produção de textos (BRASIL, 2015, p. 10, grifo nosso).

No relatório de 2018, no entanto, aparece o termo decodificação, fortemente criticado nos cadernos de formação do Pnaic:

A decodificação do alfabeto é uma aprendizagem fundamental, mas para que os indivíduos possam ler e produzir textos com autonomia é necessário que eles consolidem as correspondências grafofônicas ao mesmo tempo em que vivenciem diferentes situações de uso, de aplicação da leitura e da produção de textos (BRASIL, 2018c, p. 21, grifo nosso).

Percebe-se que, apesar de trazer um texto com algumas palavras coincidentes, o documento assume outra concepção de alfabetização. Enquanto o documento de 2015 traz termos como "apropriação da escrita" e "vivências de atividades de leitura e produção de texto", que pressupõem a consideração de um sujeito que interage ativamente com o objeto de conhecimento, o documento de 2018 menciona "decodificação do alfabeto", "uso e aplicação da leitura e produção de texto”. A escolha desses termos não é arbitrária, mas carregada de sentidos, pois a utilização dos verbos usar e aplicar pressupõe uma visão técnica dessa aprendizagem, dando um sentido de execução, cumprimento de normativas ou reprodução do que foi ensinado.

Outra diferença visível é em relação ao entendimento do papel das matrizes de referência em uma avaliação de larga escala na etapa de alfabetização. No documento de 2015, percebe-se um posicionamento que, coerente com a teoria que o embasa, mostra a concepção de que há fatores técnicos, políticos e pedagógicos envolvidos na escolha do que será analisado em uma matriz de referência, e que ela possui limitações, pois não consegue abarcar a complexidade desses fatores. Relativiza-se, então, esses resultados:

\begin{abstract}
Uma vez que a aprendizagem não pode ser medida de maneira direta, necessita-se identificar, por meio de um construto e das teorias que o sustentam, as características relacionadas à aprendizagem que sejam diretamente perceptíveis. [...] Desse modo, a matriz retrata uma opção por determinados saberes e informações que representem o construto examinado, o que não nega a existência de outros saberes ou informações significativas que podem contribuir para a visão dele. Muitas vezes, alguns conhecimentos/informações ficam de fora da matriz, dadas às limitações dos instrumentos destinados à avaliação em larga escala. Por essa razão, afirma-se que a matriz de referência se constitui como um recorte de determinada realidade. Em outras palavras, a escolha dos saberes e eixos analisados deriva de opções com embasamento técnico, político e pedagógico. Esse recorte é justificado tanto pelas limitações dos instrumentos de aplicação de uma avaliação de larga escala quanto por uma opção política sobre o que deve ser melhorado e analisado em um dado construto (BRASIL, 2015, p. 15).
\end{abstract}

No documento de 2018, no entanto, há uma compreensão diferente e, ao invés de relativizar, atribui-se um caráter absoluto e positivista aos resultados:

O desenvolvimento de uma avaliação em larga escala como a ANA tem como fundamento suas Matrizes de Referência, pois são estes os documentos que orientam a elaboração dos itens, a elaboração dos pré-testes e testes, o planejamento da aplicação, a interpretação pedagógica das escalas de proficiência e a análise dos resultados. As Matrizes consistem em uma seleção de habilidades que devem refletir o fenômeno a ser mensurado (denominado tecnicamente de "construto"). No caso 
da ANA, as Matrizes especificam com clareza o que será medido em relação à alfabetização e ao letramento em língua portuguesa e à alfabetização matemática dos estudantes matriculados no $3^{\circ}$ ano do ensino fundamental (BRASIL, 2018c, p. 22).

Dessarte, é compreensível que a forma de analisar os resultados também seja diferente nas duas versões dos relatórios sobre a ANA: enquanto o primeiro considerava o processo, o segundo considerava os produtos finais. Dessa forma, antes mesmo de se publicar os resultados da avaliação aplicada em 2016, o que foi feito em agosto de 2018, o governo Temer lança, menos de dois meses após assumir o cargo da presidência, o Programa Novo Mais Educação (PNME), conforme Portaria $\mathrm{n}^{\circ}$ 1.144, de 10 de outubro de 2016, que apresentava, entre os seus objetivos, “[...] contribuir para a alfabetização, ampliação do letramento e melhoria do desempenho em língua portuguesa e matemática das crianças e dos adolescentes, por meio de acompanhamento pedagógico específico" (BRASIL, 2016, p. 23). O PNME, configurado nos moldes do Programa Mais Educação, lançado em 2007, (BRASIL, 2007b) baseia-se na ampliação da jornada escolar dos estudantes matriculados em escolas que não são de tempo integral e que apresentam baixo desempenho nas avaliações em larga escala, com a oferta de reforço escolar àqueles que apresentam dificuldades de aprendizagem.

No ano seguinte, a Portaria $n^{\circ} 826$, de 7 de julho de 2017, trouxe outros encaminhamentos para o Pnaic, articulando-o ao PNME e revogando a Portaria no 867 (BRASIL, 2012a), que instituiu originalmente o Pnaic.

Segundo o parágrafo $2^{\circ}$ da Portaria $n^{\circ} 826 / 2017$, as ações do Pnaic passariam a ter

[...] como foco os estudantes da pré-escola e do ensino fundamental, cabendo aos professores, coordenadores pedagógicos, gestores escolares e gestores públicos uma responsabilidade compartilhada no alcance do direito da criança de escrever, ler com fluência e dominar os fundamentos

da Matemática no nível recomendável para sua idade (BRASIL, 2017, p. 20).

No que se refere à avaliação, que consistia em um dos quatro eixos de atuação do Pnaic, conforme já aludido, não há nenhuma referência específica à continuidade da ANA, limitando-se o texto a mencionar uma "avaliação externa universal do nível de alfabetização, aplicada pelo Inep” (BRASIL, 2017, p. 20).

No esteio da articulação do Pnaic ao PNME, é lançado no governo Temer o Programa Mais Alfabetização (PMAlfa), por meio da Portaria n n 4, 04 de janeiro de 2018, que assegura que “O Programa Mais Alfabetização, bem como o Pacto Nacional pela Alfabetização na Idade Certa - Pnaic, regulamentado no âmbito da Portaria MEC n ${ }^{\text { 826, de }} 7$ de julho de 2017, integrarão a Política Nacional de Alfabetização.” (BRASIL, 2018a, p. 16, grifo nosso).

A Portaria $n^{\circ} 4 / 2018$, no mês seguinte à sua publicação, foi modificada, por meio da Portaria $n^{\circ} 142$, de 22 de fevereiro de 2018, que incluiu no texto a referência à BNCC para fundamentar a antecipação para o segundo ano do ensino fundamental da avaliação dos estudantes. Sem fazer menção direta à ANA, indica-se que "o Programa, em especial o desempenho das unidades escolares vulneráveis, será objeto de avaliações de impacto com o intuito de gerar evidências para seu aperfeiçoamento.” (BRASIL, 2018b, p. 54). A aplicação das avaliações, no componente língua portuguesa, tem como objetivo verificar se, ao final do $2^{\circ}$ ano, o estudante compreende "o funcionamento do sistema alfabético de escrita", apresenta "autonomia de leitura" e se apropriou "de estratégias de compreensão e de produção de textos”. (BRASIL, 2018b, p. 54).

O PMAlfa baseia-se em um sistema de reforço escolar aos estudantes que apresenta dificuldades de aprendizagem, efetuado por um assistente de alfabetização, em um período de 5 horas semanais, para as escolas 
consideradas "não vulneráveis", e de 10 horas semanais, para as "escolas vulneráveis", sendo consideradas vulneráveis as escolas em que mais de $50 \%$ dos estudantes tivessem obtido resultados em níveis insuficientes na ANA e "nível socioeconômico muito baixo, baixo, médio baixo e médio" (BRASIL, 2018b, p. 55).

Note-se que esse programa é lançado quase dez meses antes da publicação do relatório referente aos resultados da terceira edição da ANA, aplicada em 2016, e que, levando-se em conta o fato de que o Pnaic foi instituído em 2012, a primeira e a segunda edição dessa avaliação não podiam servir como referência para verificar seus efeitos, pois somente em 2015 se completaria o primeiro ciclo de alfabetização de uma criança que tivesse iniciado seu processo em 2013. No entanto, como não foi aplicada uma edição da ANA em 2015, um ciclo completo de alfabetização, depois da instituição do Pnaic, foi avaliado pela primeira vez em 2016.

É importante ressaltar, ainda, que um processo formativo, assim como afirma Imbernón (2002, p. 69) não envolve apenas “[...] atualização científica, pedagógica e cultural do professor, e sim, sobretudo, a descoberta da teoria para organizá-la, fundamentá-la, revisá-la e combatê-la, se preciso”. Nessa perspectiva, nos cadernos de formação da proposta original do Pnaic, a formação havia sido tratada de modo processual, considerando o professor alfabetizador como protagonista de sua formação, “[...] provocando-o com diferentes desafios e questionamentos, valorizando o conhecimento e o saber que ele já traz" (BRASIL, r. 1 rd, p. 18).

Uma formação nesses moldes, consequentemente, não pode ser pensada em curto prazo, pois é preciso que os conhecimentos sejam fundamentados e reelaborados pelo professor para que ele possa ser convencido de que precisa (ou não) modificar as suas práticas pedagógicas. Apenas em um modelo pautado na racionalidade técnica, em que se considera o professor como mero executor daquilo que foi pensado externamente por teóricos e especialistas, se espera que uma formação, oficina, palestra ou capacitação possa, imediatamente, provocar mudanças na prática docente.

Em que pese esses fatores mencionados - o tempo necessário para que a formação pudesse provocar mudanças, e o fato de que apenas um ciclo de alfabetização havia sido completado até 2016 - os resultados da ANA foram utilizados como justificativa para o lançamento do PMAlfa em janeiro de 2018.

A interlocução do programa com a BNCC, mais especificamente com a terceira versão desse documento, que, como mencionamos anteriormente, recebeu críticas importantes de associações ligadas a professores e pesquisados da comunidade científica, pode ser observada na descrição das diretrizes do PMAlfa, entre elas a de “[...] estipular metas do Programa entre o MEC, os entes federados e as unidades escolares participantes, no que se refere à alfabetização das crianças do $1^{\circ}$ ano e do $2^{\circ}$ ano do ensino fundamental, considerando o disposto na BNCC” (BRASIL, 2018b, p. 5).

Com a mudança na gestão do Governo Federal, devido ao pleito eleitoral, o PMAlfa vive momentos de incertezas. Há, em 2019, apenas três ofícios relativos ao programa, um publicado em abril de 2019, no qual informa que "as escolas participantes do PMAlfa no ano de 2018, que realizaram a confirmação de adesão para o ano de 2019, [...] estão autorizadas a iniciarem o Programa para este ciclo de 2019” (BRASIL, 2019b, p. 1), outro de 3 setembro de 2019, em que se pede que as escolas verifiquem, antes de utilizarem os recursos, se há discrepância nos valores (BRASIL, 2019c), e o último, de 6 de setembro de 2019, em que se orienta “[...] a todas as escolas participantes do Programa que NÃO executem os recursos recebidos” (BRASIL, 2019d, p. 1) e aguardem as instruções do MEC. 
Logo no início de seu mandato, Bolsonaro instituiu mudanças importantes na Política Nacional de Alfabetização, com a publicação do Decreto n 9.765, de 11 de abril de 2019, que consolida inflexões na concepção de alfabetização difundida pelo MEC, como pode ser observado no documento que a embasa:

Ao aprender as primeiras regras de correspondência entre grafema-fonema/fonema-grafema, a pessoa começa a decodificar, isto é, a extrair de uma sequência de letras escritas a sua forma fonológica (ou pronúncia), e a codificar, isto é, a combinar em sinais gráficos (letras ou grafemas) os sons produzidos na fala. Em outras palavras, começa a ler e a escrever (BRASIL, 2019e, p. 18-19).

Assim, o MEC assume oficialmente uma concepção altamente criticada nas políticas voltadas à alfabetização anteriores, desde a publicação dos Parâmetros Curriculares Nacionais em 1997, em que a alfabetização tem sido compreendida como a apropriação de um sistema notacional, o que implica que tanto os elementos que o compõem como a relação entre tais elementos não são predeterminados (FERREIRO, 2011; MORAIS, 2012). Ao contrário, na Ciência Cognitiva da Leitura, que tem o método fônico como principal meio de operacionalização do ensino, a alfabetização é conceituada como a aprendizagem de um código, o que significa que todos os elementos e suas relações estão predeterminados, sendo condição suficiente para a alfabetização que os sujeitos consigam discriminá-los (visual e auditivamente), memorizando-os por meio de uma técnica que seria ensinada por outrem que já conhece e utiliza o código.

$\mathrm{Na}$ história da educação brasileira, já foram presenciadas outras tentativas de tornar o método fônico oficial:

\begin{abstract}
Como exemplo recente, no âmbito da alfabetização, tem-se a tentativa dos propositores do método fônico, que, não tendo conseguido impor sua proposta com base no estabelecimento de parcerias com órgãos do Ministério da Educação (MEC), por meio da mobilização de setores da imprensa e de procedimentos lobísticos, tiveram aprovado, na Câmara dos Deputados, relatório que recomenda a adoção oficial desse método no Brasil, conforme material elaborado por esses pesquisadores e apresentado no Seminário "O Poder Legislativo e a alfabetização infantil", ocorrido em 2003. Apesar dessa aprovação por parte do Poder Legislativo (Brasil, 2003), em 2006, o Ministro da Educação, Fernando Haddad, por meio da Secretaria de Educação Básica do MEC, promoveu o seminário "Letramento e alfabetização em debate", a fim de avaliar, juntamente com pesquisadores da universidade, a pertinência (ou não) de o MEC assumir oficialmente essa proposta do método fônico na formulação e implementação de políticas públicas para a educação e a alfabetização no Brasil. Embora pesasse a aprovação por parte do Poder Legislativo, ao fim a proposta não foi assumida pelo MEC (MORTATTI, 2010, p. 339).
\end{abstract}

O debate acadêmico promovido à época pelo Ministério da Educação, que acabou levando o Governo Federal a não assumir a proposta aprovada pelo Poder Legislativo, não ocorreu em 2019. O governo atual lançou por decreto uma decisão unilateral sobre os rumos das políticas públicas voltadas para a alfabetização e formação de professores alfabetizadores no Brasil, sem chamar à discussão as entidades representativas de professores ou pesquisadores da área.

Na chamada Ciência Cognitiva da Leitura, há a ênfase no desenvolvimento de habilidades de prontidão anteriores ao início efetivo da alfabetização, o que explica o fato de a Política Nacional de Alfabetização voltar sua atenção também para a educação infantil:

[...] a Ciência Cognitiva da Leitura permite analisar com clareza quais as competências e habilidades ou requisitos que o aluno precisa ter para aprender a ler de forma adequada. Ao mapear essas habilidades [...] torna-se possível saber por onde devemos começar um curso de alfabetização. Se o aluno não possui as competências (ou não tem prontidão, na linguagem da primeira metade do século passado) precisa adquiri-las antes de dar o passo seguinte (OLIVEIRA, 2004, p.38). 
Consequentemente, por não considerar a aprendizagem do sistema de escrita alfabética como processual e conceitual, houve o dimensionamento da antecipação do período em que se espera que as crianças estejam plenamente alfabetizadas: no Pnaic, considerava-se o $3^{\circ}$ ano como o momento de consolidação da alfabetização; no PMAlfa, o $2^{\circ}$ ano; e na atual Política Nacional de Alfabetização do governo Bolsonaro, antecipou-se para o $1^{\circ}$ ano, com a seguinte justificativa:

A priorização da alfabetização no $1^{\circ}$ ano do ensino fundamental é uma diretriz de implementação da PNA que beneficia sobretudo as crianças mais pobres, visto que estas, diferentemente das crianças de nível socioeconômico mais elevado, muitas vezes não encontram em casa o estímulo a práticas de literacia e por isso costumam ter mais dificuldades em aprender a ler e a escrever. Ora, um ensino sistemático e explícito das habilidades relacionadas à alfabetização ajuda a superar essas dificuldades decorrentes da condição socioeconômica (BRASIL, 2019d, p. 42).

Observa-se, assim, que a referida política compreende a alfabetização, de forma semelhante ao final do século XIX e início do século XX no Brasil, como uma questão de ensino, e não de aprendizagem. Desde que o professor siga fielmente o método, ou seja, execute passo a passo o que for instruído a fazer, qualquer dificuldade de aprendizagem será superada.

No entanto, conforme Contreras (2002, p. 224), os professores precisam ser convencidos da legitimidade dessas propostas, sendo tratados como pessoas que compreendem "a complexidade de seu trabalho", não como executores técnicos do que foi planejado e decidido externamente à sua profissão, o que, na atual Política Nacional de Alfabetização, foi feito por decreto.

\section{Considerações Finais}

A análise das ações do Ministério da Educação voltadas à alfabetização nos últimos quatro anos sinalizam as inflexões na concepção de alfabetização nos programas empregados por três gestores diferentes - Dilma Rousseff, Michel Temer e Jair Bolsonaro. Conforme Mortatti (2010, p. 329), no decorrer da história da alfabetização brasileira, as políticas públicas têm estado "[...] diretamente relacionadas a disputas pela hegemonia de projetos políticos e educacionais", revelando, ainda, uma tendência "[...] a reduzir esse processo a aspectos neutros e meramente técnicos, porque considerados correspondentes à verdade científica comprovada e inquestionável".

Nesse sentido, as opções por determinado aspecto da alfabetização, ou mesmo por determinado método, não são decisões meramente técnicas ou neutras, mas relacionadas a um projeto político, social e econômico específico.

Para os professores alfabetizadores que trabalham em escolas públicas, as mais diretamente impactadas pelas políticas educacionais, sobretudo aqueles que participaram de formações continuadas anteriores, ficam incertezas e questionamentos: o que fazer com os anos de investimento em conhecimentos sobre os processos de aprendizagem do sistema de escrita alfabética? Como agir diante dessas inflexões advindas do governo federal? Devem-se abandonar os saberes construídos até então e simplesmente obedecer às demandas normativas oficiais?

A forma como a Política Nacional de Alfabetização foi instituída, ignorando-se e se sobrepondo à política anterior, colocando um entendimento sobre alfabetização, dentre os vários que existem, como certeza, ou seja, "evidência científica", em uma postura positivista, demonstra a necessidade de que haja, no Brasil, a consolidação de políticas de Estado e não de Governo, a fim de que os gestores, sejam aqueles que assumem o cargo após serem 
democraticamente eleitos, sejam os que o assumem por outros motivos, não se sintam autorizados a modificar os rumos de um projeto educativo que foi exaustivamente debatido entre o governo e as entidades representativas de setores da sociedade diretamente interessados ou afetados por essas decisões.

Quando se parte de uma compreensão de ciência não como verdade absoluta, mas como uma aproximação relativa do conhecimento que é possível se construir em determinado momento histórico, percebe-se que as tensões aqui tratadas foram provocadas não somente pelas inflexões na concepção de alfabetização, mas, principalmente, pela falta de espaço para o diálogo e discussão dos vários pontos de vista, ou vistas de um ponto, antes de se modificar os projetos em andamento.

Para Mortatti (2010, p. 329, grifo nosso), as políticas públicas referem-se ao “[...] conjunto de ações coletivas voltadas para a garantia dos direitos sociais, configurando um compromisso público que visa dar conta de determinada demanda, em diversas áreas".

No entanto, o que se presenciou nas políticas educacionais a partir de 2016, e com maior ênfase em 2019, foi o esvaziamento do espaço de debate, bem como a desconsideração do compromisso público que havia sido firmado pelos entes federados em 2012. As certezas assumidas no governo Bolsonaro, no que se refere à adoção de um método de alfabetização como solução para os problemas educacionais, não refletem a busca por evidências científicas, mas uma inflexibilidade que não se aproxima, nem de longe, do pensamento acadêmico e científico.

\section{Referências}

ALVES, Raphael Gomes. Entrevistado por União Nacional dos Dirigentes Municipais de Educação (Undime). In: UNDIME. Notícias: ANA: as ações federais para a alfabetização em 2018. [s.1.]: [s.n.], 10 nov. 2017. Disponível em: https://undime.org.br/noticia/10-11-2017-14-30-ana-as-acoes-federaispara-a-alfabetizacao-em-2018. Acesso em 04 out. 2019.

BRASIL. Parâmetros Curriculares Nacionais. Brasília: MEC, SEF, 1997.

BRASIL. Decreto n 6.094, de 24 de abril de 2007. Dispõe sobre a implementação do Plano de Metas Compromisso Todos pela Educação [...]. Diário Oficial da União, Brasília, n. 79, seção 1, p. 5-6, 25 abr. 2007a.

BRASIL. Portaria normativa interministerial $n^{\circ} 17$, de 24 de abril de 2007. Institui o Programa Mais Educação. Diário Oficial da União, Brasília, n. 80, seção 1, p. 5, 26 abr. 2007 b.

BRASIL. Portaria nº 867, de 4 de julho de 2012. Institui o Pacto Nacional pela Alfabetização na Idade Certa e as ações do Pacto e define suas diretrizes gerais. Diário Oficial da União, Brasília, DF, $2012 \mathrm{a}$.

BRASIL. Pacto Nacional pela Alfabetização na Idade Certa: caderno de apresentação. Brasília: MEC, SEB, 2012b. 
BRASIL. Pacto Nacional pela Alfabetização na Idade Certa: a aprendizagem do sistema de escrita alfabética. Brasília: MEC, SEB, 2012c.

BRASIL. Pacto Nacional pela Alfabetização na Idade Certa: formação de Professores no Pacto Nacional pela Alfabetização na Idade Certa. Brasília: MEC, 2012d.

BRASIL. Avaliação Nacional da Alfabetização (ANA): documento básico. Brasília: INEP, 2013.

BRASIL. Relatório da Avaliação Nacional da Alfabetização (ANA) 2013-2014: análise dos resultados. Brasília: INEP, 2015 (v. 2).

BRASIL. Portaria $n^{\circ} 1.144$, de 10 de outubro de 2016. Institui o Programa Novo Mais Educação, que visa melhorar a aprendizagem em língua portuguesa e matemática no ensino fundamental. Diário Oficial da União, Brasília, n.196, seção 1, p. 16, 11 de out. 2016.

BRASIL. Portaria n ${ }^{\circ}$ 826, de 7 de julho de 2017. Dispõe sobre o Pnaic. Diário Oficial da União, Brasília, n. 130, Seção 1, p. 20, 10 jul. 2017.

BRASIL. Portaria $n^{\circ} 4$, de 4 de janeiro de 2018. Institui o Programa Mais Alfabetização, que visa fortalecer e apoiar as Unidades Escolares no processo de alfabetização dos estudantes regularmente matriculados nos $1^{\circ}$ e $2^{\circ}$ anos iniciais do ensino fundamental. Diário Oficial da União, Brasília, n. 4, seção 1, p. 15-16, 06 jan. 2018a.

BRASIL. Portaria $\mathrm{n}^{\circ}$ 142, de 22 de fevereiro de 2018. Institui o Programa Mais Alfabetização, que visa fortalecer e apoiar as Unidades Escolares no processo de alfabetização dos estudantes regularmente matriculados nos $1^{\circ}$ e $2^{\circ}$ anos iniciais do ensino fundamental. Diário Oficial da União, Brasília, n. 37, seção 1 , p. 54-55, 2018 b.

BRASIL. Relatório Saeb/ANA 2016: panorama do Brasil e dos estados. Brasília: MEC/SEB, 2018c.

BRASIL. Ministério da Educação. Casa Civil. Decreto nº 9.765, de 11 de abril de 2019. Institui a Política Nacional de Alfabetização. Diário Oficial da União, Brasília, Seção 1, Edição Extra - A, p. 15, 11 abr. 2019a.

BRASIL. Ministério da Educação. Ofício-Circular No 5/2019/COEF/DICEI/SEB/SEB-MEC. Assunto: Programa Mais Alfabetização - PMAlfa - Reabertura do ciclo 2019. Brasília, 5 de abril de 2019a. Disponível em: https://undime.org.br. Acesso em 04 out. 2019b.

BRASIL. Ministério da Educação. Ofício-Circular No 10/2019/COEF/DPR/SEB/SEB-MEC.

Assunto: URGENTE - Programa Mais Alfabetização - PMAlfa. Recursos 2019. Brasília, 6 set. 2019c. Disponível em: https://undime.org.br. Acesso em 04 out. 2019c.

BRASIL. Ministério da Educação. Ofício nº 90/2019/DPR/SEB/SEB-MEC. Assunto: URGENTE Programa Mais Alfabetização - PMAlfa. Recursos 2019. Brasília, 6 set. 2019d. https://undime.org.br. Acesso em 04 out. 2019.

BRASIL. Política Nacional de Alfabetização. Brasília: MEC, SEALF,2019e. 
CONTRERAS, José. Autonomia de professores. São Paulo: Cortez, 2002.

HEINSFELD, Bruna Damiana; SILVA, Maria Paula Rossi Nascentes da. As versões da Base Nacional Comum Curricular (BNCC) e o papel das tecnologias digitais: conhecimento da técnica versus compreensão dos sentidos. Currículo sem Fronteiras, [s.1.], v. 18, n. 2, p. 668-690, maio/ago. 2018.

FERREIRO, Emília; TEBEROSKY, Ana. Psicogênese da Língua Escrita. 3.ed. Porto Alegre: Artes Médicas, 1985.

FERREIRO, Emília. Reflexões sobre Alfabetização. São Paulo: Cortez, 2011.

FRADE, Isabel Cristina Alves da Silva. Métodos e didáticas de alfabetização: história, características e modos de fazer dos professores. Belo Horizonte: Ceale/FaE/UFMG, 2005. (Coleção Alfabetização e Letramento).

IMBERNÓN, Francisco. Formação docente e profissional: formar-se para a mudança e a incerteza. São Paulo: Cortez, 2002.

MINISTÉRIO DA EDUCAÇÃO. Ministro da Educação anuncia mudanças no sistema de avaliação a partir de 2019. In: Portal do Ministério da Educação [on line]: Notícias, Brasília, 28 jun. 2018. Disponível em: http://portal.mec.gov.br. Acesso em 08 out. 2019.

MORAIS, Artur Gomes de. Sistema de escrita alfabética. São Paulo: Melhoramentos, ${ }^{\top} \cdot{ }^{\prime}$. (Como eu ensino).

MORTATTI, Maria do Rosário Longo. Alfabetização no Brasil: conjecturas sobre as relações entre políticas públicas e seus sujeitos privados. Revista Brasileira de Educação, Rio de Janeiro, v. 15, n. 44, p. 329-341, 2010.

OLIVEIRA, João Batista Araujo e. Alfabetização de crianças e adultos: novos parâmetros. 5. ed. Belo Horizonte: Alfa Educativa, 2004.

PROJETO LEITURA E ESCRITA NA EDUCAÇÃO INFANTIL. Posicionamento do Projeto Leitura e Escrita na Educação Infantil em relação à terceira versão da BNCC. Belo Horizonte: ABALF, 2017. Disponível em: www.abalf.com.br. Acesso em 04 out. 2019.

SILVA, Ceris Salete Ribas da. Ciclos de alfabetização. In: FRADE, Isabel Cristina da Silva; VAL, Maria da Graça Costa; BREGUNCI, Maria das Graças de Castro. (Org.). Glossário Ceale: termos de alfabetização, leitura e escrita para educadores. Belo Horizonte: UFMG/Faculdade de Educação, 2014. p. 1 .

SOUSA, Sandra Novais; NOGUEIRA, Eliane Greice Davanço. A alfabetização no Pnaic e "Alfa e Beto": (im)possibilidades teóricas. Saarbrucken, Alemanha: Novas Edições Acadêmicas, 2016. 


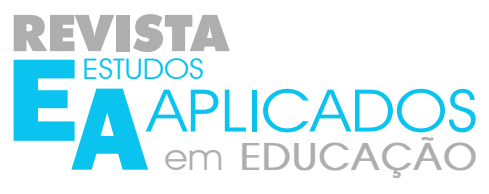

VIÉDES, Silvia Cristiane Alfonso. Políticas públicas em alfabetização: o Pacto Nacional pela Alfabetização na Idade Certa no município de Anastácio - MS. 2015. 148 f. Dissertação (Mestrado Profissional em Educação) - Universidade Estadual de Mato Grosso do Sul, Campo Grande, 2015.

Recebido em: 13/10/2019

Aprovado em: 04/12/2019 